\title{
Effect of Age on Primary Balloon Dacryocystoplasty and Probing Success in Congenital Nasolacrimal Duct Obstruction
}

Volkan Dericioğlu ( $\square$ volkandr@gmail.com )

Marmara University School of Medicine https://orcid.org/0000-0001-6264-5304

Mehmet Orkun Sevik

Marmara Universitesi Tip Fakultesi

Sena Sümmen Saçu

Marmara Universitesi Tip Fakultesi

Muhsin Eraslan

Marmara Universitesi Tip Fakultesi

Eren Cerman

Marmara Universitesi Tip Fakultesi

\section{Research Article}

Keywords: probing, primary balloon dacryocystoplasty, congenital nasolacrimal duct obstruction, age, effect, CNLDO

Posted Date: September 29th, 2021

DOI: https://doi.org/10.21203/rs.3.rs-931424/v1

License: (c) (i) This work is licensed under a Creative Commons Attribution 4.0 International License. Read Full License 


\section{Abstract}

Purpose: To compare the success rates of balloon dacryocystoplasty (BDP) and probing as a primary procedure in congenital nasolacrimal duct obstruction (CNLDO) and investigate the effect of age on both procedures.

Methods: A total of 135 patients (171 eyes) with simple or incomplete complex CNLDO were included in this retrospective study; complete complex CNLDO cases were excluded. The success rates for primary BDP (118 eyes) and for probing (53 eyes) were compared as overall and among the age groups; Group 1 (12-24 months old), Group 2 (25-36 months old), and Group 3 (> 36 months old).

Results: Mean age of the patients was $41.5 \pm 27.2$ months for primary BDP, and $21.8 \pm 10.8$ months for probing $(p<0.001)$. Overall success rates for primary BDP and probing were $81.1 \%(43 / 53)$ and $76.3 \%$ $(90 / 118)$, respectively $(p=0.481)$. Success rates for BDP and probing among age groups were, $93.8 \%$ and $85.3 \%$ in Group 1 ( $p=0.306), 93.3 \%$ and $50.0 \%$ in Group 2 ( $p=0.012$ ), and $63.6 \%$ and $27.3 \%$ in Group 3 $(p=0.052)$, respectively. Cox regression analysis showed that the median ages were 18 months for probing and 36 months for primary BDP. Poisson regression model showed that, for every one-month increase in patients' age, the success rate of probing decreased by $9.7 \%$.

Conclusion: Probing success decreased to a point where different treatment options such as primary BDP can be discussed with the patient's parents after 18 months of age. The success of BDP decreased after 36 months, while it maintained a high success rate between 24-36 months as primary treatment.

\section{Introduction}

Congenital nasolacrimal duct obstruction (CNLDO) is a clinical condition characterized by epiphora, crusting on the lashes, and mucopurulent secretion. A large-scale cohort study showed that CNLDO occurs in one out of nine newborn children, which makes the condition a public health problem [1].

The resolution rate for CNLDO with medical management, such as with topical antibiotics and Crigler massage, is approximately $75-90 \%[2,3]$, which does not differ from the resolution rate for early probing before 12 months of age [3,4]. Due to these similar resolution rates, probing has been recommended for patients with persistent symptoms after the first year of life [3]. Although probing is accepted as the firstline treatment for persistent CNLDO, controversial reports have discussed the procedure's optimal timing and resolution rates with patients' advancing age; while some authors reported a significant decrease in success rates for late probing $[5,2,6,7]$, others found that age did not significantly affect success rates $[8,4,9]$.

Balloon dacryocystoplasty (BDP) is an alternative treatment option for CNLDO, alongside nasolacrimal intubation and dacryocystorhinostomy. In general, BDP is used as a second-line treatment in primary probing failure cases, with a reported success rate of 74-94\% [10]. In addition, some authors have reported that BDP offers a good outcome when used as a primary treatment for CNLDO, especially 
among older children and different obstruction types [11-16]. On the other hand, to our best knowledge, there are only two studies in the literature that compared probing versus BDP as primary treatment $[17,18]$. While Gunton et al. [17] design a study comparing the results of both procedures in age-matched children, Goldrich et al. [18] compared the results in different age groups. However, the efficacy of BDP compared to probing as a first-line procedure has yet to be determined [19].

This study aims to compare the results of probing and primary BDP for the patients with different age groups, to investigate the age at which surgical success rate reduces for primary probing, and to determine BDP's optimal timing as a first-line treatment.

\section{Materials And Methods}

In this single-center study, we retrospectively investigated the success rates of probing and primary BDP applied to 135 patients (171 eyes) for simple or incomplete complex CNLDO between 2011 and 2018. The study protocol was approved by the Institutional Review Board of Marmara University School of Medicine (No: 09.2015.210), and the study was performed in accordance with the Declaration of Helsinki principles.

CNLDO was diagnosed based on the patient's history and clinical examination. Eyes with the presence of epiphora, high tear meniscus, mucopurulent discharge without any signs of conjunctivitis, trauma, or ocular disease, with the history of symptoms onset before 6 months of age and the presence of mucopurulent discharge with lacrimal massage were evaluated as CNLDO. Suspected cases were confirmed by the fluorescein dye disappearance test. Accordingly, one drop of $2 \%$ fluorescein solution was instilled in the lower conjunctival fornices of both eyes, and if the stain did not clear from the lacrimal lake after five minutes had passed, it was evaluated as an obstruction.

The types of obstruction were determined according to probing results by retrospectively evaluating patients' surgical notes. As previously described [5], complete complex CNLDO was defined as patients for whom a probe could not reach the nasal cavity, and metal-to-metal contact could not be received due to a firm bony obstruction, and these cases were excluded from the study. In addition, patients with dacryocystocele, a history of acute dacryocystitis, craniofacial anatomical abnormalities, any genetic syndrome, and fewer than six-month follow-up times were also excluded from the study. Only simple and incomplete complex patients who had received metal-to-metal contact at the inferior meatus, and whose patency was open with an irrigation-aspiration test were included. Written informed consent was obtained from all of the patient's legal guardians before the operations.

In our clinical practice, the procedure applied to the patients was determined according to the cut-off age of 24 months. However, to present the success of BDP and probing procedures at different ages, patients outside this cut-off value were randomly selected into the different operation groups.

All procedures were performed under inhalation anesthesia with a laryngeal mask in operating-room by the same surgeon (EÇ). After dilatation of the upper punctum, a Bowman's probe (no. 0 or 00 ) was 
inserted vertically to the punctum and advanced through the canaliculus on the horizontal plane. After reaching the nasal wall, it was rotated 90 degrees to a vertical position and advanced through the nasolacrimal duct. After feeling the membrane rupture, confirmation was made by metal-to-metal contact, fluorescein-stained saline irrigation, and aspiration with a pediatric aspiration catheter placed in the lower meatus.

For patients undergoing BDP, after the probing procedure was performed, a LacriCath balloon catheter (Quest Medical, Allen, Texas, USA), selected according to the patient's age, was placed in the lacrimal duct in the deflated position. For patients aged 24 months and younger, $2 \mathrm{~mm}$ size was used. For patients older than 24 months, a $3 \mathrm{~mm}$ size was used. The balloon was pushed to the marked area at a distance of $15 \mathrm{~mm}$ proximally, and it was then inflated twice, first at 8 bars for 90 seconds and then for 60 seconds, and dilatation of the nasolacrimal duct's distal end was ensured. The balloon was then withdrawn to the second mark at $10 \mathrm{~mm}$ and inflated for 90 seconds, and the dilatation of the nasolacrimal duct's proximal end was ensured. Next, the balloon was deflated and removed. At the end of the procedure, the nasolacrimal duct passage was checked once more by irrigation-aspiration, and then the operation terminated. Patients for whom metal-to-metal contact or irrigation-aspiration were not possible were excluded from the study and referred for further evaluation. A topical netilmicin $0.3 \%$ and dexamethasone $0.1 \%$ eyedrop treatment was applied during the first week after the procedure.

All patients were re-evaluated at one week, one month, three months, and six months postoperatively. As success criteria, ophthalmologic examinations and fluorescein disappearance tests of the eyes were performed at the six-month follow-up after the procedure. A procedure was accepted as successful if there was no presence of epiphora upon examination with a lacrimal massage, no clinical signs of CNLDO, and no fluorescein stain at the fifth minute of the fluorescein disappearance test. If these criteria were not met, the operation was considered as failure.

The IBM SPSS Statistics for Macintosh program, Version 24, was used for statistical analysis. A Kolmogorov-Smirnoff test was used for case distribution, and since the study population was nonparametrically distributed in terms of age, a Mann-Whitney $U$ test was used. Patients were divided into three groups according to their ages: Group 1, 12-24 months old; Group 2, 25-36 months old; and Group 3 , older than 36 months. Age groups were compared via a chi-square test. A statistical correlation was made by the Pearson correlation test. A Poisson regression model was used to calculate risk ratios and 95\% confidence intervals (C.I.s). Cox regression analysis was used to determine the median age for a successful intervention. A p-value less than 0.05 was considered statistically significant.

\section{Results}

In total, 53 eyes of 44 patients who had undergone primary BDP and 118 eyes of 91 patients who had undergone primary probing were evaluated. The mean follow-up time for all cases was $57.3 \pm 18.8$ (6116) months. The patient characteristics are shown in Table 1. No complications were noted for either group. The mean ages of the patients were $41.5 \pm 27.2$ (range, 12-120) in the BDP group and 
$21.8 \pm 10.8$ (range, $12-60$ ) months in the probing group ( $p<0.001$ ). Bilaterality was $20.5 \%$ and $29.7 \%$ for the primary BDP and probing, respectively, and no significant correlation was observed between success rates and bilaterality $(\mathrm{p}=0.150)$. Overall primary BDP success rate was $81.1 \%$ (43 of 53 eyes), whereas the probing success rate was $76.3 \%$ (90 of 118 eyes) $(p=0.481$ ) (Table 1 ).

Table 1. Clinical characteristics of the patients and overall success rates in probing and primary BDP groups.

\begin{tabular}{llll|} 
& Probing & BDP & p-Value* \\
\hline Patients / Eyes, $n$ & $91 / 118$ & $44 / 53$ & - \\
\hline Female / Male, $\mathrm{n}$ & $51 / 67$ & $29 / 24$ & - \\
\hline Bilaterality, $\mathrm{n}(\%)$ & $27(29.7)$ & $9(20.5)$ & - \\
Age as Months, & $21.8 \pm 10.8$ & $41.5 \pm 27.2$ & $<0.001$ \\
mean \pm SD, & $(12-60)$ & $(12-120)$ & \\
(range) & & & 0.481 \\
Overall Success, $\mathrm{n}(\%)$ & $97(77.6 \%)$ & $43(81.1 \%)$ &
\end{tabular}

$B D P$, balloon dacryocystoplasty; $S D$, standard deviation

*Mann-Whitney U test

Success rates for primary BDP and probing among the age groups were, $93.8 \%$ and $85.3 \%$ in Group 1 $(p=0.306), 93.3 \%$ and $50.0 \%$ in Group 2 ( $p=0.012)$, and $63.6 \%$ and $27.3 \%$ in Group 3 ( $p=0.052)$, respectively. Additionally, for probing, the success rate was better in Group 1 than Group $2(p=0.003)$ and $3(p<0.001)$, and for primary BDP, success rates were better in Group $1(p=0.033)$ and $2(p=0.041)$ than Group 3. Success rates of the primary BDP and probing according to age groups were summarized in Table 2. 


\section{Table 2}

Success rates of probing and primary BDP according to age groups.

Group 1 Group 2 Group $3 \quad p$-Value*

\section{2-24 Months 25-36 Months >36 Months}

\section{Probing}

$\begin{array}{lllll}\text { Success } / \mathrm{n} & 81 / 95 & 6 / 12 & 3 / 11 & \text { Group 1 vs. 2, } 0.003 \\ \text { Success Rate } & 85.3 \% & 50 \% & 27.3 \% & \text { Group 1 vs. 3, }<0.001 \\ & & & & \text { Group 2 vs. 3, } 0.275\end{array}$

\section{Primary BDP}

$\begin{array}{lllll}\text { Success } / \mathrm{n} & 15 / 16 & 14 / 15 & 14 / 22 & \text { Group } 1 \text { vs. 2, } 0.963 \\ \text { Success Rate } & 93.8 \% & 93.3 \% & 63.6 \% & \text { Group 1 vs. 3, } \mathbf{0 . 0 3 3} \\ & & & & \text { Group 2 vs. 3, 0.041 }\end{array}$

$\begin{array}{llll}\text { p-Value }^{\star} & 0.360 & \mathbf{0 . 0 1 2} & 0.052\end{array}$

$B D P$, balloon dacryoplasty.

${ }^{*}$ Chi-square test

A likelihood ratio chi-square test indicated that the full model offered a significant improvement in fit over a no-predictors model $(\mathrm{p}<0.05)$. A Poisson regression model showed that age significantly predicted success for the probing group $(p=0.042)$ but not for the BDP group $(p=0.368)$. The incidence rate ratio indicated that, for every one-month patients' age, the success rate of probing decreased by $9.7 \%$ (C.I.s 95\%: 9.5\%-9.9\%). A Cox regression analysis showed that the median ages were 18 months (C.I.s 95\%: 16.5-19.4) for probing and 36 months (C.I.s 95\%: 29.8-42.2) for primary BDP, and the log-rank difference was statistically different between these groups $(\mathrm{p}<0.001)$ (Figure 1$)$.

\section{Discussion}

In this study, we analyzed the results of primary BDP and probing for persistent CNLDO at different age groups in order to identify the optimal age at which to use BDP as a primary treatment. This study showed that the overall success rates of both procedures were similar in simple and incomplete complex CNLDO, but the age groups evaluations revealed the primary BDP offers better success rates after 24 months of old.

The success rate of probing was decreased by $9.7 \%$ for every one-month increase in patients' age, and the median timing for successful probing was found to be 18 months of age in simple or incomplete 
complex CNLDO in this study. Similarly, a large cohort study by Sathiamoorthi et al. showed that probing's success rates decreased with increasing patient ages and reported an $89 \%$ resolution rate from primary probing in 289 eyes, while children probed at 15 months or older experienced lower resolution rates [2]. Recently, Świerczyńska et al. showed that probing success rates decreased dramatically with increasing patient age and one-third of operations ultimately failed after patients reached 24 months of age, regardless of their obstruction type [7]. In the present study, the probing success rate was significantly decreased between the age of $24-36$ months (Group 1 vs. Group 2, p = 0.003). Additionally, the probing success rate fell to $27 \%$ in patients older than 36 months (Group 3). Strict complete success criteria and a small number of patients in Group 3 could explain the high failure rate in this study.

In general, nasolacrimal probing is recommended as a first-line treatment for persistent CNLDO after 12 months of age. According to different patient age groups, there are variable results for probing in the literature, making the timing of intervention controversial $[2,7,4,9]$. Many surgeons prefer other procedures than primary probing for patients at older months of age. In a published questionnaire survey among 119 members of the American Association for Pediatric Ophthalmology and Strabismus, $53 \%$ of physicians preferred primary BDP or silicone tubes if probing treatment was delayed until 24 months of age [20]. Furthermore, this rate increased to $68 \%$ if probing treatment was delayed until 36 months of age. In our practice, we prefer primary BDP instead of silicon tubes because of the possibility of the focal damage to the punctum and canaliculus, extrusion of the stent, and corneal damage previously reported with silicon tubes [19].

BDP is a well-known procedure; however, there are limited numbers of study comparing primary BDP and probing in the literature. We found that primary BDP was slightly more successful than probing in terms of overall success rates ( $81.1 \%$ vs. $76.3 \%, p=0.481$ ), even though the primary BDP patients were significantly older than the probing patients $(41.5 \pm 27.2$ vs. $21.8 \pm 10.8$ months, $p<0.001)$. Similar to our study, Goldich et al. [18] also reported no significant differences between the overall success rates of primary BDP and probing ( $89.5 \%$ vs. $86.7 \%, p=0.548)$ at significantly different mean ages $(55.9 \pm 113.6$ vs. $18.5 \pm 6.5$ months, $p<0.01$ ). Additionally, the authors reported that the patient's age had no significant effect on either surgery [18]. Gunton B. et al. conducted a study in which the mean ages of primary BDP and probing were similar ( $31.1 \pm 13.5$ vs. $37.1 \pm 25.2$ months, respectively, $p=0.36$ ) [17]. They reported no significant difference between primary BDP and probing either in overall success rates $(90 \%$ vs. $86 \%$, respectively, $\mathrm{p}=0.22$ ) or in different age groups [17]. In contrast, we found that primary BDP yielded significantly better results than probing after 24 months of age. In Group 2 (patients aged 25-36 months), we observed a highly significant difference in success rates of primary BDP (93.3\%) and probing $(50 \%)(p=0.012)$. This result seems to be due to a significant decrease in probing's success rate since no difference was observed in BDP's success rate until patients reached 36 months (BDP, Group 1: $93.8 \%$, Group 2: $93.3 \%, p=0.963)$.

One of our study's important results is that the success of primary BDP decreased significantly after patients reached 36 months of age compared to the other age groups. Group 3's primary BDP success rate significantly reduced to $63.6 \%$ from $93.3 \%(p=0.041)$. A previous study about primary BDP reported 
the procedure's success rate at $100 \%$ before patients reached 24 months $(n=5)$, decreasing to $75.9 \%$ for children older than 24 months ( $n=29)$ (mean age: 35.6 months). Still, this result was not statistically significant $(p=0.526)$ [12]. Another study, conducted by the Pediatric Eye Disease Investigator Group, showed that primary BDP's failure rate was $14 \%$ for patients between 12 and 24 months old, and this rate increased to $25 \%$ for patients between 24 and 48 months old (mean age: 23 months) [15]. Although the failure rate was reported to increase with patients' age, no statistical evaluation was reported between these two groups [15]. Interestingly, in the recent research by Gazit I. et al., it was found that the primary BDP success rate was significantly decreased after 36 months of age, quite similar to our study [16]. This success reduction in these studies, including ours, could be explained by persistent and late-intervened CNLDO's ability to result in increased adhesions and fibrosis in the nasolacrimal duct [6]. BDP's effectiveness may decrease when opening these tighter adhesions for older patients.

Our study contributes to filling the literature's gap insufficient results for primary BDP versus primary probing at patients' different ages [19]; however, it faces some limitations. Due to this study's retrospective nature, we could not specify patients' types of occlusions. However, only patients who had metal-to-metal contact per-operatively and whose patency was controlled by irrigation-aspiration were included in the study. These inclusion criteria resulted in a cohort that included both simple and incomplete complex CNLDO cases. Given that complete complex CNLDO is rare and mostly seen in syndromic patients [5,21], we can conclude that our study results suggest patient age's effect on probing and primary BDP for the remaining major patient population. Future studies can prospectively divide the definition of incomplete complex occlusion into more detailed stages and investigate the effect of patient age on these stages and primary BDP's success rate.

Secondly, the fact that endoscopy was not used in the study can be considered a limitation. Although the early study about endoscopy-assisted probing concluded that endoscopy usage is not required in most cases [22], more recent studies reported positive results using endoscopy in CNLDO [23,24]. However, a recent survey from the United Kingdom showed that while $43.9 \%$ of oculoplastic consultants were using nasoendoscopy, only $12.9 \%$ of pediatric consultants were [25]. Considering that the primary treatment of a prevalent disease such as CNLDO is also applied by general ophthalmologists, it can be predicted that the overall rate of endoscopy use is lower than these rates. Therefore, the present study has illuminating aspects about these two procedures performed conventionally without using an endoscope.

In conclusion, amid the ongoing debate about the optimal timing and more favorable surgical choices for CNLDO, this study suggests that after a cut-off point of 18 months, probing success decreases to a level that other options such as primary BDP could be discussed with the patient's parents. However, no significant difference was found in primary BDP success for patients between 12 and 24 months with simple and incomplete complex CNLDO. Moreover, due to the decrease in BDP's success rate after the age of 36 months, BDP may be chosen as a primary treatment with an excellent success rate, especially for children between 24 and 36 months of age.

\section{Declarations}




\section{Author contributions:}

All authors contributed to the study's conception and design. Material preparation, data collection and analysis were performed by Sena Sümmen, Mehmet Orkun Sevik, Eren Çerman and Volkan Dericioğlu. The draft was written by Volkan Dericioğlu and all authors commented on previous versions of the manuscript. All authors read and approved the final manuscript.

\section{Funding:}

This research did not receive any specific grant from funding agencies in the public, commercial, or notfor-profit sectors.

\section{Conflict of interest:}

All authors certify that they have no affiliations with or involvement in any organization or entity with any financial interest.

\section{Ethical approval:}

All procedures performed in studies involving human participants were in accordance with the ethical standards of the Institutional Ethics Committee of Marmara University (Istanbul, Turkey) and with the 1964 Helsinki declaration and its later amendments or comparable ethical standards.

\section{Consent to participate:}

Consent and approval were obtained from the Institutional Ethics Committee of Marmara University (Istanbul, Turkey) to process the data of patients' records in this retrospective study.

\section{Availability of data and material:}

Raw data were generated at Marmara University School of Medicine Ophthalmology Department. Derived data supporting the findings of this study are available from the corresponding author (VD) on request.

\section{References}

1. Sathiamoorthi S, Frank RD, Mohney BG (2019) Incidence and clinical characteristics of congenital nasolacrimal duct obstruction. Br J Ophthalmol 103(4):527-529. doi:10.1136/bjophthalmol-2018312074 
2. Sathiamoorthi S, Frank RD, Mohney BG (2018) Spontaneous Resolution and Timing of Intervention in Congenital Nasolacrimal Duct Obstruction. JAMA Ophthalmol 136(11):1281-1286. doi:10.1001/jamaophthalmol.2018.3841

3. Kakizaki H, Takahashi Y, Kinoshita S, Shiraki K, Iwaki M (2008) The rate of symptomatic improvement of congenital nasolacrimal duct obstruction in Japanese infants treated with conservative management during the 1st year of age. Clin Ophthalmol 2(2):291-294. doi:10.2147/opth.s2582

4. Investigator PEyeD, Repka G, Chandler MX, Beck DL, Crouch RW, ER, 3rd, Donahue, Holmes S, Lee JM, Melia K, Quinn M, Sala GE, Schloff NA, Silbert S, Wallace DI DK (2008) Primary treatment of nasolacrimal duct obstruction with probing in children younger than 4 years. Ophthalmology 115(3):577-584 e573. doi:10.1016/j.ophtha.2007.07.030

5. Kashkouli MB, Beigi B, Parvaresh MM, Kassaee A, Tabatabaee Z (2003) Late and very late initial probing for congenital nasolacrimal duct obstruction: what is the cause of failure? $\mathrm{Br} \mathrm{J}$ Ophthalmol 87(9):1151-1153. doi:10.1136/bjo.87.9.1151

6. Katowitz JA, Welsh MG (1987) Timing of initial probing and irrigation in congenital nasolacrimal duct obstruction. Ophthalmology 94(6):698-705. doi:10.1016/s0161-6420(87)33392-5

7. Swierczynska M, Tobiczyk E, Rodak P, Barchanowska D, Filipek E (2020) Success rates of probing for congenital nasolacrimal duct obstruction at various ages. BMC Ophthalmol 20(1):403. doi:10.1186/s12886-020-01658-9

8. Ciftci F, Akman A, Sonmez M, Unal M, Gungor A, Yaylali V (2000) Systematic, combined treatment approach to nasolacrimal duct obstruction in different age groups. Eur J Ophthalmol 10(4):324-329

9. Robb RM (1998) Success rates of nasolacrimal duct probing at time intervals after 1 year of age. Ophthalmology 105(7):1307-1309. doi:10.1016/S0161-6420(98)97038-5 discussion 1309-1310.

10. Takahashi Y, Kakizaki H, Chan WO, Selva D (2010) Management of congenital nasolacrimal duct obstruction. Acta Ophthalmol 88(5):506-513. doi:10.1111/j.1755-3768.2009.01592.x

11. Lueder GT (2002) Balloon catheter dilation for treatment of older children with nasolacrimal duct obstruction. Arch Ophthalmol 120(12):1685-1688. doi:10.1001/archopht.120.12.1685

12. Tao S, Meyer DR, Simon JW, Zobal-Ratner J (2002) Success of balloon catheter dilatation as a primary or secondary procedure for congenital nasolacrimal duct obstruction. Ophthalmology 109(11):2108-2111. doi:10.1016/s0161-6420(02)01216-2

13. Yuksel D, Ceylan K, Erden O, Kilic R, Duman S (2005) Balloon dilatation for treatment of congenital nasolacrimal duct obstruction. Eur J Ophthalmol 15(2):179-185

14. Chen PL, Hsiao CH (2005) Balloon dacryocystoplasty as the primary treatment in older children with congenital nasolacrimal duct obstruction. J AAPOS 9(6):546-549.

doi:10.1016/j.jaapos.2005.08.002

15. Investigator PEyeD, Repka G, Melia MX, Beck BM, Chandler RW, Fishman DL, Goldblum DR, Holmes TA, Perla JM, Quinn BD, Silbert GE, Wallace DI DK (2008) Primary treatment of nasolacrimal duct 
obstruction with balloon catheter dilation in children younger than 4 years of age. J AAPOS 12(5):451-455. doi:10.1016/j.jaapos.2008.07.001

16. Gazit I, Pras E, Or L, Hartstein ME (2021) Balloon catheter dilation as the primary treatment of congenital nasolacrimal duct obstruction. Eur J Ophthalmol 31(2):334-339. doi:10.1177/1120672119895906

17. Gunton KB, Chung CW, Schnall BM, Prieto D, Wexler A, Koller HP (2001) Comparison of balloon dacryocystoplasty to probing as the primary treatment of congenital nasolacrimal duct obstruction. J AAPOS 5(3):139-142. doi:10.1067/mpa.2001.115218

18. Goldich Y, Barkana Y, Zadok D, Avni I, Pras E, Mezer E, Morad Y (2011) Balloon catheter dilatation versus probing as primary treatment for congenital dacryostenosis. $\mathrm{Br} J$ Ophthalmol 95(5):634-636. doi:10.1136/bjo.2010.183301

19. Wladis EJ, Aakalu VK, Yen MT, Bilyk JR, Sobel RK, Mawn LA (2018) Balloon Dacryoplasty for Congenital Nasolacrimal Duct Obstruction: A Report by the American Academy of Ophthalmology. Ophthalmology 125(10):1654-1657. doi:10.1016/j.ophtha.2018.05.005

20. Dotan G, Nelson LB (2015) Congenital nasolacrimal duct obstruction: common management policies among pediatric ophthalmologists. J Pediatr Ophthalmol Strabismus 52(1):14-19. doi:10.3928/01913913-20141028-01

21. Ali MJ, Kamal S, Gupta A, Ali MH, Naik MN (2015) Simple vs complex congenital nasolacrimal duct obstructions: etiology, management and outcomes. Int Forum Allergy Rhinol 5(2):174-177. doi:10.1002/alr.21435

22. Orhan M, Cal P, Onerci M, Irkec M (2001) Conventional or endoscopic probing for congenital nasolacrimal duct obstruction. Eur J Ophthalmol 11(3):215-217

23. Galindo-Ferreiro A, Khandekar R, Akaishi PM, Cruz A, Galvez-Ruiz A, Dolmetsch A, Schellini S (2018) Success Rates of Endoscopic-Assisted Probing Compared to Conventional Probing in Children 48 Months or Older. Semin Ophthalmol 33(3):435-442. doi:10.1080/08820538.2017.1284872

24. Gupta N, Neeraj C, Smriti B, Sima D (2018) A comparison of the success rates of endoscopicassisted probing in the treatment of membranous congenital nasolacrimal duct obstruction between younger and older children and its correlation with the thickness of the membrane at the Valve of Hasner. Orbit 37(4):257-261. doi:10.1080/01676830.2017.1383483

25. Golash V, Kaur H, Athwal S, Chakartash R, Laginaf M, Khandwala M (2020) Management of congenital nasolacrimal duct obstruction: results of a national survey of paediatric and oculoplastic ophthalmologists. Eye (Lond). doi:10.1038/s41433-020-01183-5

\section{Figures}




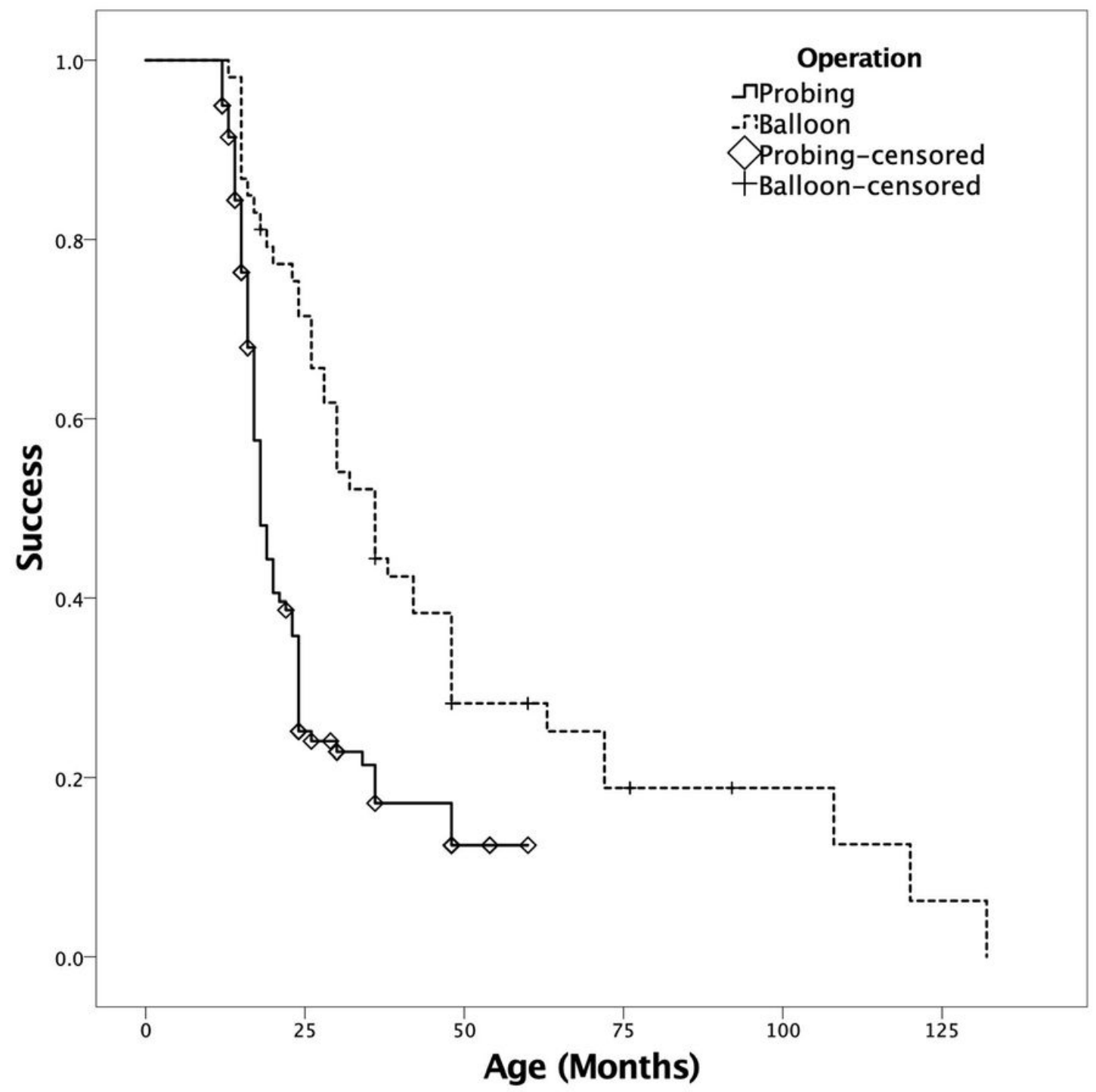

Figure 1

Cox regression analysis for probing and primary balloon dacryocystoplasty. 